\title{
A novel TOPSIS-CBR goal programming approach to sustainable healthcare treatment
}

\author{
Hanif Malekpoor ${ }^{1} \cdot$ Nishikant Mishra ${ }^{2} \cdot$ Sameer Kumar ${ }^{3}$ \\ Published online: 3 August 2018 \\ (c) The Author(s) 2018
}

\begin{abstract}
Cancer is one of the most common diseases worldwide and its treatment is a complex and time-consuming process. Specifically, prostate cancer as the most common cancer among male population has received the attentions of many researchers. Oncologists and medical physicists usually rely on their past experience and expertise to prescribe the dose plan for cancer treatment. The main objective of dose planning process is to deliver high dose to the cancerous cells and simultaneously minimize the side effects of the treatment. In this article, a novel TOPSIS case based reasoning goal-programming approach has been proposed to optimize the dose plan for prostate cancer treatment. Firstly, a hybrid retrieval process TOPSIS-CBR [technique for order preference by similarity to ideal solution (TOPSIS) and case based reasoning $(\mathrm{CBR})]$ is used to capture the expertise and experience of oncologists. Thereafter, the dose plans of retrieved cases are adjusted using goal-programming mathematical model. This approach will not only help oncologists to make a better trade-off between different conflicting decision making criteria but will also deliver a high dose to the cancerous cells with minimal and necessary effect on surrounding organs at risk. The efficacy of proposed method is tested on a real data set collected from Nottingham City Hospital using leave-one-out strategy. In most of the cases treatment plans generated by the proposed method is coherent with the dose plan prescribed by an experienced oncologist or even better. Developed decision support system can assist both new and experienced oncologists in the treatment planning process.
\end{abstract}

Keywords Case based reasoning · Goal-programming · Prostate cancer · Radiotherapy · TOPSIS

Nishikant Mishra

mishra09@gmail.com

1 Norwich Business School, University of East Anglia, Norwich, UK

2 Hull University Business School, University of Hull, Hull, UK

3 Opus College of Business, University of St. Thomas, Minneapolis, MN, USA 


\section{Introduction}

Cancer is a disease where cells in a particular segment of the body proliferate abnormally. Usually, cancer begins in one part of the body and spread to other parts and affects the functionality of host and surrounding healthy organs. This process is known as metastasis. Prostate cancer is the most common cancer in the male population (Cancer Research UK, http://www.cancerresearchuk.org). In 2011, about 42,000 of cases of prostate cancer were reported in UK and there were about 11,000 deaths caused by the same in 2012. In order to prevent abnormal growth of cancerous cells, radiotherapy treatment is generally prescribed in combination with other treatments. In radiotherapy treatment X-rays or gamma rays are used to kill the cancerous cells. Radiation used in the treatment not only kills the cancerous cells but also affects the surrounding normal organs. Prostate is a tiny and delicate gland located at the base of bladder and surrounded by the urethra and rectum. Rectum is very sensitive and usually taken care of by the oncologist during treatment process. Radiotherapy planning is a complex and time-consuming process. Oncologists and medical physicists use different software to determine suitable combination of different planning parameters such as number of wedges and its configuration, number of beams, beam weight and angle between the beams and dose in different phases of treatment, etc. In real life, oncologists in cooperation with medical physicists perform several experiments through trial and error method to find suitable values of above-mentioned parameters essential for the treatment. In this article, we have focused on addressing the issues related to dose planning in radiotherapy treatment.

Appropriate dose planning has been recognized as a crucial part of cancer treatment and in past several methods has been developed to address this problem. Romeijn et al. (2006) proposed a linear programming approach to radiotherapy dose planning problem. The main constraints of the developed model were hard bounds on the dose limits for normal and cancerous cells. In this approach, various dose-planning parameters were fixed before the optimization, which is not an easy task. Their exact values may vary from patient to patient. In addition to that, this method could generate only one treatment plan at a time. It forces the planner to launch a succession of experiments if multiple plans or compromises are desired. Fiege et al. (2011) proposed a multi-objective algorithm to optimize Intensity-Modulated Radiation Therapy (IMRT) using Genetic Algorithm. In this approach the Pareto for optimum solutions is built using multi-objective Genetic Algorithm (GA). However, deciding which treatment option in the Pareto frontier is the most appropriate is tedious and a complex task.

In order to deal with a new problem, the past solutions that were developed to solve the similar problem are good indicator to remind us what solutions were successful and which of them failed. Furthermore these past experiences could teach us about the factors essential to success and also causing failure. Case-based reasoning is a general paradigm for reasoning from experience. It uses a memory model for representing, indexing, and organizing past cases and a process model for retrieving and modifying old cases and assimilating new ones (Slade 1991; Yin et al. 2015). Case-based reasoning, a knowledge-based system is a problem-solving approach that relies on past similar cases to find out solutions to new problem (Kolodner 1993; Ayeldeen et al. 2015; Begum et al. 2011). CBR has proven to be especially applicable to problem solving and decision support in the health sciences. Application of CBR to analyze and integrate case histories and abundant anecdotal evidence on individual patients' treatment by different doctors can lead to more reliable accounts and treatments (Bichindaritz and Marling 2006). There have been several attempts to improve cancer decision support by use of CBR in recent years. Teodorovic et al. (2013) has used case based reasoning approach for dose planning in thyroid cancer. In this approach they have used Bee Colony optimization for assigning weights to various criteria measuring similarities between new case and cases 
in the database. Ping et al. (2015) proposed a multiple measurements case-based reasoning (MMCBR) method for liver cancer recurrence predictive models. This approach used pairing method through time series and dynamically determined matching pairs among cases and paired all cases in the database with new case. In this method, various similarity measures were considered but results were not outstanding. Sharaf-El-Deen et al. (2014) combined case based reasoning with rule based reasoning in order to improve the accuracy of case based reasoning. Both case based reasoning and rule based reasoning used information generated from database and did not consider any extra information.

Multi Criteria Decision Making (MCDM) is a methodological framework that aims to provide decision makers a knowledgeable recommendation among a finite set of alternatives, actions, objectives or solutions (Chai et al. 2013). Now-a-days decisions are becoming more and more complex and involve various factors. In order to select best alternative among several available solutions decision makers usually make a trade-off between different conflicting criteria. Application of MCDM frameworks is rapidly increasing due to its capability to improve the quality of decision making by making the process more explicit, rational and efficient than classical methods of decision-making (Oliveira et al. 2013) or decisions made by human brain, which can consider limited amount of information at one time. MCDM tools and techniques have been applied in many domains and successfully helped the process of decision making, including sustainable energy management (Streimikiene et al. 2012; Garcia-Bernabeu et al. 2016), transportation and logistics (Tzeng and Huang 2012; Tadic et al. 2014), supply chain management (Govindan and Sivakumar 2016; Malviya and Kant 2016), budgeting (Tsai et al. 2010; Tang and Chang 2012) and managerial and strategic planning (Banihabib et al. 2016). MCDM methods are also frequently applied within health care field. Decisions in health care area are extremely sensitive and significant, and involve several uncertainties and complexities. They include multiple and often conflicting criteria and objectives simultaneously and have to consider preferences and judgments of decision makers. Thus MCDM frameworks can be very helpful to support these decisions. The researches done in health care with MCDM techniques can be categorized in four main categories: priority setting management, public health and policy, service evaluation and diagnosis and treatment. Taghipour et al. (2011) applied Analytic Hierarchy Process (AHP) to prioritize medical devices in a hospital based on their significance so that devices with higher priority score should be considered more critical and special priority is assigned to them in maintenance planning. Rahimi et al. (2015) proposed a combined framework of AHP and Analytic Network Process (ANP) to prioritize the patients to be referred to surgery. In this research by using fuzzy soft sets and MCDM methods uncertainty involved in the waiting list prioritization were robustly dealt with and risk and patients medical criteria were simultaneously considered. Santos and Garcia (2010) used AHP, Multi-Attribute Failure Mode Analysis (MAFMA) and ELECTRE to demonstrate a decision model for incorporating indicators in the acquisition of hospital medical equipment.

Kahraman et al. (2014) applied Fuzzy AHP to evaluate different research investment alternatives and overcome the difficulty of measuring intangible criteria by using fuzzy sets and not only considered cost, but also considered various criteria for this evaluation and selection of best alternative. Liu et al. (2014) applied MCDM techniques to select an optimal technology for the disposal of health-care waste (HCW). In the decision making process they have considered both qualitative and quantitative factors and selected the best alternative using novel hybrid MCDM model. The proposed model amalgamates the beauty of 2-tuple DEMATEL techniques and fuzzy MULTIMOORA method.

Büyüközkan et al. (2011) compared fuzzy AHP with SERVQUAL (service quality) methodology in order to evaluate quality of service in some pioneer Turkish hospitals and 
came up with the conclusion that MCDM technique can preserve the evaluation with improved consensus. Chang (2014) proposed a framework based on the concept of fuzzy sets theory and the VIKOR technique to provide a systematic process for evaluating the hospital service quality where the uncertainty, subjectivity and vagueness exist. They selected five medical centres in Taiwan as their case study and evaluated the centres through a comprehensive empirical research by considering multiple criteria and applying linguistic terms which were parameterised by triangular fuzzy numbers.

MCDM techniques have been widely applied within diagnosis and treatment area, and in this paper, which is also the main area to which we applied our approach. Ferrari et al. (2005) applied TOPSIS to evaluate Triptan treatment options in migraine. In the proposed method tradeoff between conflicting criteria are made and seven available Triptan used in the treatment process are ranked using TOPSIS methodology. Hartati et al. (2012) used Elimination and Choice Translating Reality (ELECTRE) method to design a multi-criteria Group Decision Support System to determine whether a person has abnormal gene that can cause cancer. Using TOPSIS method, La Scalia et al. (2011) developed a decision support system for pancreatic islet transplantation. The proposed system can help doctor to calculate the probability of transplant success in relation to four classes of identified variables (donor, organ, isolation and recipient). Hummel et al. (2012) applied Analytic Hierarchy Process (AHP) to evaluate the outcome of clinical antidepressant treatment. Firstly, relative importance of different decision making criteria such as remission of depression, response to drug treatment and no relapse, etc. were determined. Thereafter, alternatives were evaluated based on the weighted criteria. Table 1 shows other recent researches done related to diagnosis and treatment by means of MCDM frameworks.

Oncology is a subsection of diagnosis and treatment, which also drew the attention of few researchers in application of MCDM techniques and is the main subject of this research. Chung et al. (2012) applied AHP to prioritize performance measures for colorectal cancer care to facilitate the implementation of a pay-for-performance (PFP) system. They used questionnaires responded by 48 doctors to assign the weight of criteria and their importance in order to prioritize performance measures. Beside, Multi Attribute Decision Making literature,

Table 1 Recent researches applying MCDM in diagnosis and treatment

\begin{tabular}{|c|c|c|}
\hline References & MCDM method(s) & Subject \\
\hline Diaz-Ledezma and Parvizi (2013) & AHP & $\begin{array}{l}\text { Evaluation of treatment methods } \\
\text { for cam femoroacetabular }\end{array}$ \\
\hline Uzoka et al. (2011) & Fuzzy AHP & DSS for diagnosis of Malaria \\
\hline Brasil Filho et al. (2009) & ELECTRE IV & Early diagnosis of Alzheimer \\
\hline Vidal et al. (2010) & AHP & $\begin{array}{l}\text { Anticancer drug production } \\
\text { process }\end{array}$ \\
\hline Othman et al. (2015) & TOPSIS & $\begin{array}{l}\text { Psychological Analysis of } \\
\text { seafarers distraction roots }\end{array}$ \\
\hline BONDOR et al. (2013) & VIKOR & $\begin{array}{l}\text { Identification of diabetic kidney } \\
\text { disease risk factors }\end{array}$ \\
\hline Piegat and Salabun (2015) & AHP-TOPSIS & $\begin{array}{l}\text { Assessing the severity of chronic } \\
\text { liver disease }\end{array}$ \\
\hline Balubaid and Basheikh (2016) & AHP & $\begin{array}{l}\text { Choosing best medicine for } \\
\text { patients with diabetes }\end{array}$ \\
\hline Lopez and Gunasekaran (2015) & Fuzzy VIKOR & Selection of vaccination strategy \\
\hline
\end{tabular}


reviewed previously, Multi Objective optimization also has been applied widely over various field of health-care domain. Marques et al. (2012) proposed an integer linear programming model to maximize the use of surgical suits. In the proposed approach rescheduling the elective surgery from waiting list maximizes efficiency of resources installed in surgical suits. They also developed heuristic to improve the non-optimal solutions. Güray and Güler (2013) proposed a hierarchical goal-programming (HGP) model to address scheduling problem of residents and the senior academic staff to outpatient clinics (OCs) in a physical medicine and rehabilitation (PMR) department. In the past significant amount of research have been conducted using MODM approaches to deal with optimizations regarding cancer treatment planning (Pugachev and Xing 2002; Clark et al. 2008; Craft et al. 2012; Bertsimas et al. 2013; Chan et al. 2014). Most of the articles related to optimization for cancer treatment focus on beam angles and IMRT features, while there is lack of enough articles on dose planning optimization and for prostate cancer specifically.

While the works related to CBR and MCDM with a focus on diagnosis and treatment have been reviewed in the literature above, there have been some researches which have integrated the principals of both approaches and demonstrated the applicability and effectiveness of the integrated approach. However, these researches mostly focus on other domains rather than diagnosis and treatments in healthcare.

Alptekin and Büyüközkan (2011), presented an integrated approach of AHP and CBR for web based tourism destination planning. By applying AHP and linguistic words they assigned the weights to cases' attributes and then through case based reasoning and similarity between the new case and cases in case pool the appropriate services were offered to online customers. By applying AHP the accuracy of case matching can be enhanced. Li et al. (2011), applied the principle of TOPSIS to CBR to predict a business failure possibility. The distance between a case and ideal positive solutions, cases with non-failing results, and negative ideal solutions were calculated and based on the most similar case the possibility of the business failure was predicted. Armaghan and Renaud (2012) developed a CBR system in which in the retrieval process, instead of $k$-Nearest Neighbours $(k-\mathrm{NN})$ approach, they applied two outranking methods of ELECTRE I and II. Comparisons of results showed that in their industrial dataset their approach could improve the results obtained from CBR. Chuang (2013), applied a hybrid model of CBR, Rough Set Theory (RST) and Grey Relational Analysis (GRA) to enhance the performance of CBR in bankruptcy prediction. In this approach by the help of GRA, they have calculated the weights for different attributes available and then by using RST key attributes for CBR application have been carried out. Hu and Sun (2016), hybridized the principle of relative Entropy and TOPSIS and developed a new similarity measure for crisp numbers. Comparison of the developed method with Euclidean and Manhattan distance based CBR showed improvements in the results.

The main purpose of this paper is to optimize the dose plan of radiotherapy treatment by utilizing oncologists' past experiences. In earlier study conducted by Petrovic et al. (2011) a case based reasoning method was developed for radiotherapy dose planning problem. In the proposed approach firstly four most similar cases were retrieved from the database. Thereafter, retrieved cases were fused using Dempster-Shafer theory to generate a suitable dose plan for new patient. Although in real life oncologists do not make decision just based on the most similar cases treated in the past but they also take into account various other factors such as success rate and side effects of treatment. Also, sometimes to treat the cancerous cells they overlook the recommended dose constraint for different volume percentages of rectum as shown in Table 2. To accomplish this purpose in another study (Malekpoor et al. 2017) we have developed a TOPSIS-Cased Based Reasoning approach in which firstly, using case based reasoning cases similar to the new case were extracted from the database. 
Table 2 Dose limits for different volume percentage of rectum

$$
\text { Rectal volume \% }
$$

Total dose limits

66

50

25

10
45

55

65

70

Thereafter, extracted cases were evaluated using TOPSIS approach to make the tradeoff between different conflicting criteria, and the direct dose plan associated with the selected case from TOPSIS evaluation was prescribed for the new case. In experiments it was found that dose plans calculated by above approach may not be an optimal one and still there is a scope for improvement. In this study, goal programming is used to calculate the optimal dose plans for the treatment by endeavoring to achieve nearest dose plans to oncologists' ideal dose plans while considering the side effects of the treatment and avoiding risks endangering patients. This paper is organized as follow. In Sect. 2, radiotherapy dose-planning parameter is described in detail along with limitations and potential risks. In Sect. 3, proposed solution methodology is elucidated. Execution process of proposed method is demonstrated on a real case in Sect. 4. Robustness and efficacy of the proposed method is discussed in Sect. 5. In Sect. 6, conclusion and future research suggestions are provided.

\section{Problem formulation}

Radiotherapy planning for prostate cancer problem is a complex and time-consuming process. The treatment is usually performed in two stages, phase I and phase II. In phase I prostate and surrounding organs where cancer has spread is treated. While, in the second phase only prostate will be irradiated. The main objective of treatment is to kill the cancerous cells without affecting the functionality of surrounding organs. In Nottingham City Hospital usually doses are prescribed in the range of 46-64 and 16-24 Gy in Phase I and II of the treatment respectively. Prescribed total dose is usually delivered in fraction, each fraction approximately accounts for $2 \mathrm{~Gy}$. The overall process of radiotherapy treatment is explained in Fig. 1.

Radiotherapy planning process is generally performed in several steps. Oncologist examines new patient and test the level of PSA (Prostate Specific Antigen). Prostate cancer can increase the production of PSA, and so a PSA test looks for raised levels of PSA in the blood that may be a sign of the condition in its early stages. Through PSA test, Digital Rectal Examination (DRE) and biopsy the oncologists can detect prostate cancer and prescribe different clinical tests such as Computed Tomography (CT) scan and Magnetic Resonance Imaging (MRI) to determine the stage of cancer. After that, medical physicists in planning department, by considering the results of scans, sketch the tumor volume and determine the organs at risks so that, areas involved crucially within cancerous cells and the areas which contain only microscopic tumor cells can be segregated. Based on the sketched volume and characteristic of patient, different planning parameters are set by the oncologists and medical physicist. These parameters include number of beams utilized in radiation, angle between the beams, number of wedges, wedge angle. Also Dose Volume Histograms (DVHs) for both phases of the treatment have an important role to help the oncologists in prescribing a high quality treatment plan (Holder and Salter 2005). DVH is a graphical representation 


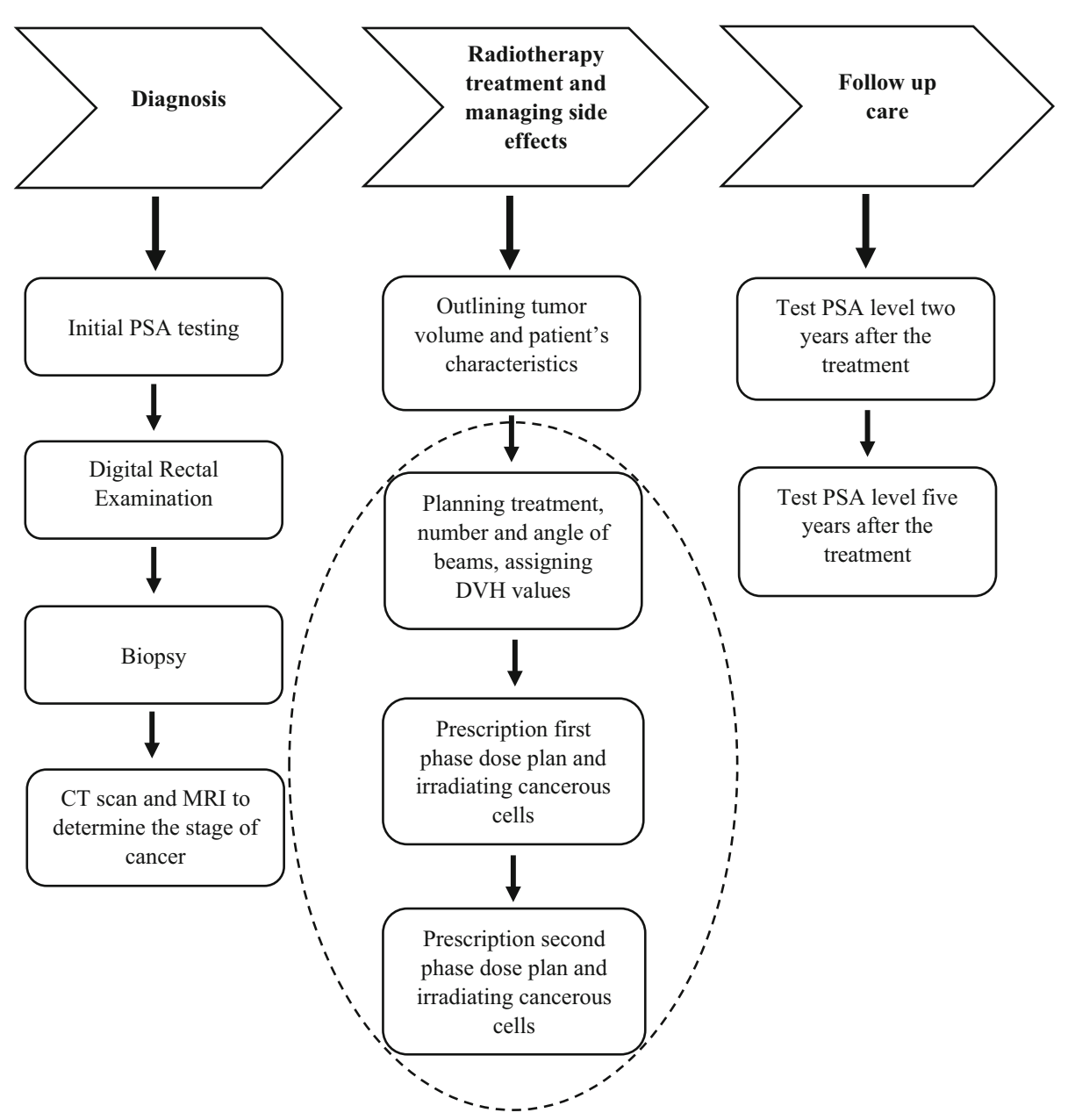

Fig. 1 Radiotherapy dose planning process

of the dose that is received by normal tissues and target volumes within a 3-D radiation therapy plan. It allows oncologists to calculate amount of radiation that would be received by different volume percentage of rectum. For example, if DVH value of $66 \%$ of rectum in phase II of treatment is 0.7 and prescribed dose in phase II of treatment is $20 \mathrm{GY}$ than the dose received by $66 \%$ of rectum will be $14 \mathrm{GY}(0.7 \times 20 \mathrm{GY}=14 \mathrm{GY})$. Based on calculated DVHs' values and Clinical stage, Gleason Score and Prostate Specific Antigen (PSA) value oncologist perform several successive experiments to determine dose in Phase I and II of the treatment so that cancerous cells can be killed effectively without impairing the normal organs near to the cancerous cells particularly bladder and rectum. Compared to bladder, rectum is very sensitive organ. In a feasible dose plan dose received by different volume percentage of rectum must be within the constraints. The recommended dose limits of different volume percentages of the rectum are given in Table 2. In some case these dose limits can be overlooked to some extent so that sufficient dose can be delivered to the cancerous cells. 


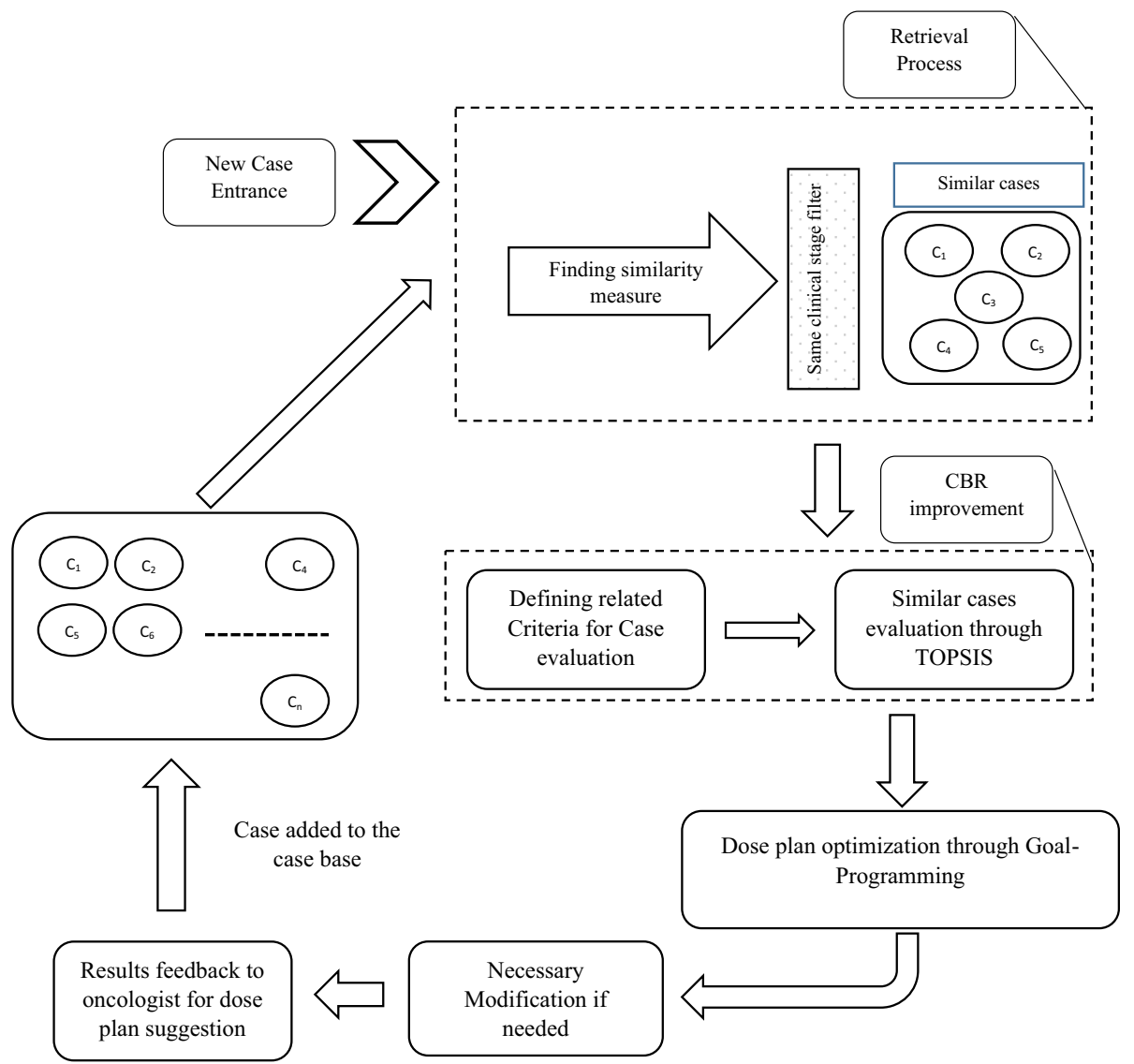

Fig. 2 Overall overview of decision-making system

\section{Solution methodology}

In the proposed approach past treated cases collected from Nottingham City Hospital are stored in a database. Each case consists of two parts; condition of the patients, which describe the outcome of different clinical examinations and dose plan (dose in phase I and II) prescribed by the oncologist. The overall framework of our proposed methodology is illustrated in Fig. 2. In the first step, cases similar to the new case are extracted from the database using case based reasoning. Thereafter, extracted cases are evaluated using TOSPIS multi-criteria decisionmaking process to make a tradeoff between success rate (maximum dose to the cancerous cells) and side effects of the treatment. Afterward, based on parameters of the most ideal case selected by TOPSIS method dose in phase I and II of the treatment is determined by multi-objective integer goal programming (GP) method. The proposed approach can help oncologist to maximize the total dose without affecting the surrounding organs. The detailed description of each stage is given in the following sub sections. 
Table 3 Features of prostate cancer treatment

\begin{tabular}{lll}
\hline Feature & Values & Type of values \\
\hline Stage of the cancer & T1a, T1b, T1c, T2a, T2b, T3a, & Ordinal \\
Gleason Score & T3b & Integer number \\
PSA & {$[1,10]$} & Real number \\
DVHs & {$[1,40]$} & Real number \\
\hline
\end{tabular}

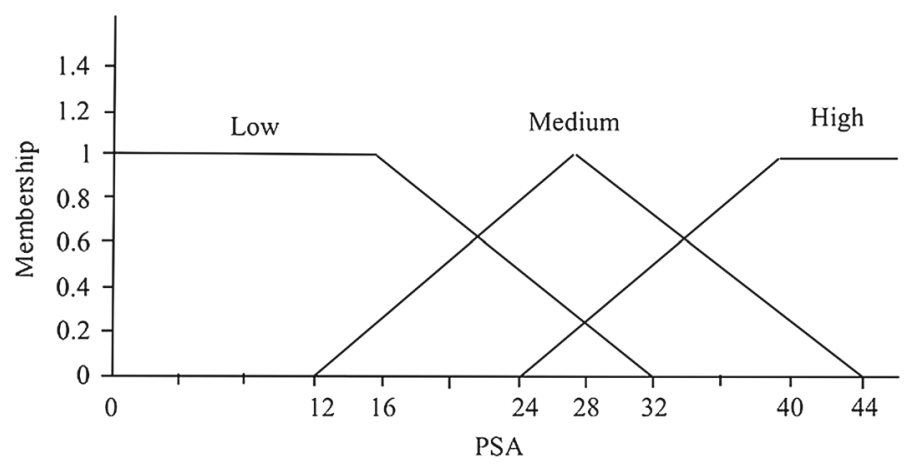

Fig. 3 PSA fuzzy membership

\subsection{Representation of the case}

In order to retrieve cases similar to the new case from the database, two groups of features i.e. clinical stage and geometry of the prostate are used to measure the similarity between a new case and cases in database. Attributes associated with these features are listed in Table 3 and "Appendix", describes these features in more details.

The data type, measurement unit and scale of aforementioned parameters are different. Thus in order to develop a comprehensive similarity measure in case based reasoning we have used fuzzy set theory to normalize these parameters in the interval of [0 1]. The parameters and values for membership functions have been set and coordinated through Nottingham University Hospital oncologists, which reflect their judgments and perceptions about Gleason Score and PSA values.

The membership functions of each feature $l$ (Gleason Score $(l=1)$, PSA $(l=2)$ ) of case $C_{p}$ are represented by a triplet $\left(v_{p l 1}, v_{p l 2}, v_{p l 3}\right)$, where $v_{p l m}, \mathrm{~m}=1,2,3$ are membership degrees of feature $l$ to fuzzy sets low $(m=1)$, medium $(m=2)$ and high $(m=3)$.

The membership functions of PSA and Gleason Score are shown in Figs. 3 and 4 respectively.

\subsection{Retrieval process of similar cases}

During the discussion with oncologist it was found that clinical stage is an important decision making criteria. Usually, patient with similar clinical stage share same kind of treatment. Clinical stage can be arranged in the following sequence $\{\mathrm{T} 1 \mathrm{a}, \mathrm{T} 1 \mathrm{~b}, \mathrm{~T} 1 \mathrm{c}, \mathrm{T} 2 \mathrm{a}, \mathrm{T} 2 \mathrm{~b}, \mathrm{~T} 3 \mathrm{a}$, $\mathrm{T} 3 \mathrm{~b}\}$. Corresponding to each new patient firstly cases having same clinical stage or adjacent 


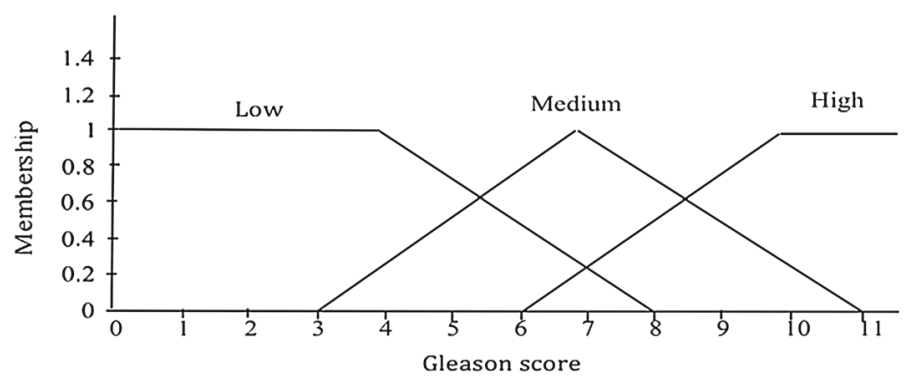

Fig. 4 Gleason score fuzzy membership

to the new case are extracted from the database. Thereafter, from the filtered list cases similar to the new case are retrieved.

Distance between new case $C_{p}$ and case in the database $C_{q}$ is calculated using Eq. (1). It takes into consideration fuzzy membership values of Gleason Score $(l=1)$ and PSA value $(l=2)$.

$$
d_{1}\left(C_{p}, C_{q}\right)=\left(\sum_{l=1}^{2} \sum_{m=1}^{3}\left(v_{p l m}-v_{q l m}\right)^{2}\right)^{\frac{1}{2}}
$$

Taking into account numerical values of different DVH volume percentage of rectum $(b=1) 66 \%,(b=2) 50 \%,(b=3) 25 \%$ and $(b=4) 10 \%$ distance between new case $C_{p}$ and case in the database $C_{q}$ is calculated using Eq. (2). In this equation $(h=1,2)$ represents the phase of treatment. $u_{p h b}$ and $u_{q h b}$ are the values of dose received for each percentage of the rectum in phase 1 and 2 of the treatment and is calculated based on DVH values.

$$
d_{2}\left(C_{p}, C_{q}\right)=\left(\sum_{h=1}^{2} \sum_{b=1}^{4}\left(u_{p h b}-u_{q h b}\right)^{2}\right)^{\frac{1}{2}}
$$

Overall similarity measure between cases $C_{p}$ and $C_{q}$ is measured using Eq. (3).

$$
S\left(C_{p}, C_{q}\right)=\frac{1}{1+d_{1}\left(C_{p}, C_{q}\right)+d_{2}\left(C_{p}, C_{q}\right)}
$$

\subsection{Solution methodology for improving CBR}

In simple case based reasoning usually decision is based on the most similar extracted case. However, sometime in radiotherapy dose-planning process the most similar case may not be the most appropriate case to make decision. In addition to similarity there are other criteria, which can have more impact on the preference of a case over other cases. In the experiment, it was found that the case which has a high similarity measure is not always the most appropriate case to make decision, because sometimes they have low success rate or dose received by different volume percentages of rectum surpass the restrictions as shown in Table 2. In order to solve the aforementioned problem firstly, cases similar to new case are retrieved from the database thereafter cases are evaluated using TOPSIS technique to make a trade-off between similarity measure, success rate and side effect of treatment. 


\subsubsection{TOPSIS methodology}

TOPSIS (Technique for Order Preference by Similarity to an Ideal Solution) is a MCDM method developed by Hwang and Yoon (1981). The main purpose of this technique is to rank different alternatives based on their distances from ideal positive and negative solution. TOPSIS can be performed using following steps:

At the beginning of the process a decision Matrix $\mathrm{D}$ is constructed. The row of each matrix represents alternatives, while column represents different criteria.

$$
D M=\left[y_{i j}\right]=\left[\begin{array}{ccc}
y_{11} & \cdots & y_{1 r} \\
\vdots & \ddots & \vdots \\
y_{n 1} & \cdots & y_{n r}
\end{array}\right]
$$

where $y_{i j}(i=1, \ldots, n ; j=1, \ldots, r)$ are the elements of the decision matrix D.

Thereafter, following steps are performed to select best alternative:

Step 1 Decision Matrix is normalized using Eq. (5):

$$
R_{i j}=\frac{y_{i j}}{\sqrt{\sum_{j=1}^{j} y_{i j}}}
$$

$R_{i j}$ is the normalized value of element $y_{i j}$ in decision matrix.

Step 2 Weighted normalized decision matrix is calculated using Eq. (6).

$$
v_{i j}=w_{i} R_{i j}
$$

Step 3 Positive and negative ideal solutions are specified using Eqs. (7) and (8) respectively:

$$
\begin{gathered}
P I S=\left\{v_{1}^{*}, \ldots, v_{r}^{*}\right\}=\left\{\begin{array}{c}
\max _{j} v_{i j} \mid i \in \text { benefit } \\
\min _{j} v_{i j} \mid i \in \text { cost }
\end{array}\right. \\
\text { NIS }=\left\{v_{1}^{-}, \ldots, v_{r}^{-}\right\}=\left\{\begin{array}{l}
\min _{j} v_{i j} \mid i \in \text { benefit } \\
\max _{j} v_{i j} \mid i \in \text { cost }
\end{array}\right.
\end{gathered}
$$

Step 4 Distance of each alternative from Positive Ideal Solutions (PIS) and Negative Ideal Solutions (NIS) are calculated using Eqs. (9) and (10) respectively.

$$
\begin{aligned}
& D_{j}^{+}=\sqrt{\sum_{i=1}^{n}\left(v_{i j}-v_{i}^{*}\right)^{2}} \\
& D_{j}^{-}=\sqrt{\sum_{i=1}^{n}\left(v_{i j}-v_{i}^{-}\right)^{2}}
\end{aligned}
$$

Step 5 Finally, relative closeness coefficient is calculated using Eq. (11) and alternative with higher coefficient is ranked better.

$$
C_{j}^{*}=\frac{D_{j}^{-}}{D_{j}^{-}+D_{j}^{+}}
$$


In our proposed method extracted cases are evaluated based on similarity measures, success rate (total prescribed dose, dose in phase I and II of treatment) and side effects of treatment (deviation from recommended dose limit of different volume percentage of rectum as given in Table 2). Similarity measure, total dose and dose in phase I of the treatment is considered as our positive weighted criteria and are given more importance than others. Dose in phase II of the treatment is considered as negative weighted criteria which means that cases having higher value of dose in phase II of treatment is given less importance in decision making process. The weights for all the criteria have been considered the same for this research. The full description of criteria can be found in Malekpoor et al. (2017).

\subsection{Optimizing the final dose plan}

During the study it was found that sometimes dose plan suggested by TOPSIS-CBR is not an optimal dose plan and there is a scope for improvement. On the other hand, sometimescalculated dose plan is not suitable for a new case. It violates recommended dose limits associated with different volume percentages of the rectum. To solve the above problem optimization of dose planning is performed using integer goal programming mathematical model, where the deviation from DVH recommended values is calculated by the help of best similar case suggested by CBR-TOPSIS. Thereafter, deviations corresponding to different volume percentages of rectum are calculated using Eq. (12):

$$
S_{v}^{p}=d_{q 1} D V H_{v}^{1 p}+d_{q 2} D V H_{v}^{2 p}-\text { Recomended standard }
$$

where $S_{v}^{p}$ represents deviation of a new case $p$ corresponding to different volume percentage of rectum $v(v=66,50,25,10 \%) . d_{q 1}$ and $d_{q 2}$ represent dose of extracted case in phase I and II of treatment respectively. $D V H^{1}$ and $D V H^{2}$ are the values for Dose Volume Histograms of the new case which are available for each new case and have been also used in finding similarity measure of the case based reasoning. An example of these values for each case is available in Table 4, columns 3-10.

This value determines the suitability of solution prescribed by CBR-TOPSIS method by calculating amount of dose received by different volume percentage of the rectum.

To treat cancerous cells, in real life sometime oncologists overlook recommended dose limit. The amount of deviation from recommended limit is usually based on oncologists' past experiences. To employ the knowledge and expertise of oncologist, in this article, deviations are calculated based on extracted past treated patients' information stored in the database.

\subsubsection{Goal programming methodology}

Goal programming is basically a multi-objective linear optimization tool, which helps solution to move towards ideal goal. Goal programming consists of following attributes: an objective function, a set of limitations related to goals and systematic constraints. The aim of objective function is to minimize deviations from the given goals as far as possible. The deviation in the objective function is usually weighted to define the priority of some of them to the others. Mathematical formulation of the goal programming is as follows:

$$
\min Z=\sum_{j=1}^{n}\left(w_{k} d_{k}^{+}+w_{k} d_{k}^{-}\right)
$$




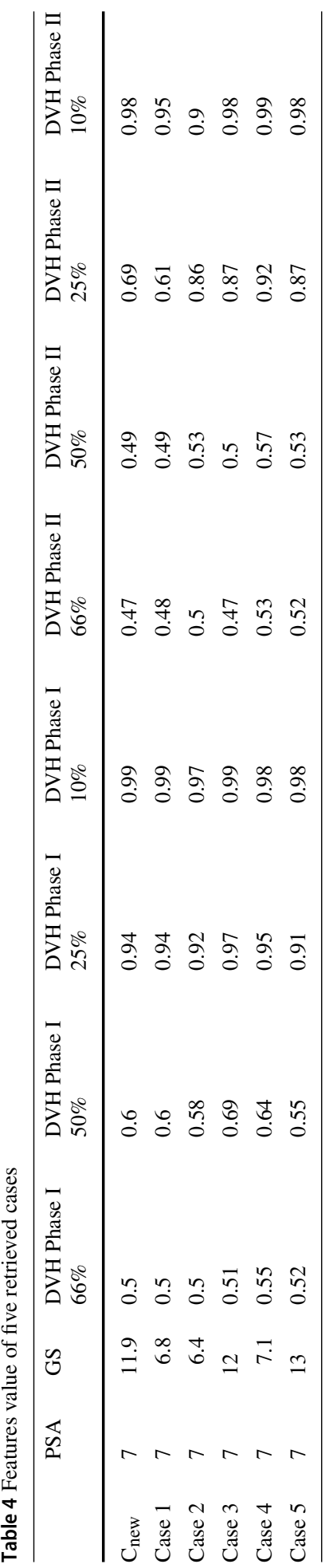


s.t.

$$
\begin{gathered}
f\left(x_{1}, \ldots, x_{i}, \ldots, x_{M}\right)_{k}-d_{k}^{+}+d_{k}^{-}=g_{k} \quad k=1,2, \ldots, n ; \text { and } i=1,2, \ldots, M ; \\
A X \leq \text { or } \geq B
\end{gathered}
$$

where $\mathrm{X}$ is a set of variables, that is, $X=\left\{x_{1}, x_{2}, \ldots, x_{M}\right\}$, A is a matrix consisting of coefficient for variables in our systematic constraints, $B$ is a matrix for right side values of systematic constraints and $g_{k}$ represents the goal corresponding to constraint $k$.

$d_{k}^{+}$and $d_{k}^{-}$are the auxiliary variables that demonstrate the upper and lower deviations from the goal $g_{k}$. In objective function, we try to minimize deviations to satisfy the goals. $w_{k}$ is the importance of the $k$ th goal compared to other goals. As can be seen, the deviations include positive and negative deviations from the considered goal. Minimization procedure is done only on the undesired deviation and thus only the undesired deviation appears in the final objective function of the problem.

If the goal is to achieve more than a certain value, then GP tries to minimize the negative deviation from the goal and positive deviation is going to be maximized automatically as much as the hard constraints allow it to and the opposite happens if the goal is to achieve less than a certain value.

If the goal is to achieve precisely equal to a value, then both of the negative and positive deviations are considered as undesired deviations and objective function tries to minimize both of the deviations.

During the discussion with oncologists it was found that the main objective of dose planning process is to maximize overall prescribed total dose while respecting the dose corresponding to different volume percentage of rectum. If the two-dose plans have same value of total dose and dose received by different volume percentage of rectum is within the constraint the dose plan having higher amount of dose in first phase of treatment is considered as a better dose plan compared to others. In this article goals are set based on abovementioned criteria. Goal objectives are as follows:

Objective 1: Goal objective of the total dose plan is to assign maximum amount of recommended dose in our case pool.

Objective 2: Goal objective of the dose in Phase I of the treatment is to deliver maximum or amount of dose prescribed in phase I in our case pool or higher.

Objective 3: Goal objective of the dose plan in Phase II of the treatment is to assign maximum amount of dose prescribed in phase II in our case pool or higher.

Figure 5 shows the Process of modeling the GP problem.

The first step is to running CBR-TOPSIS and obtain the best case corresponding to a new case. Thereafter, in the second step by using the dose prescribed by the best case from

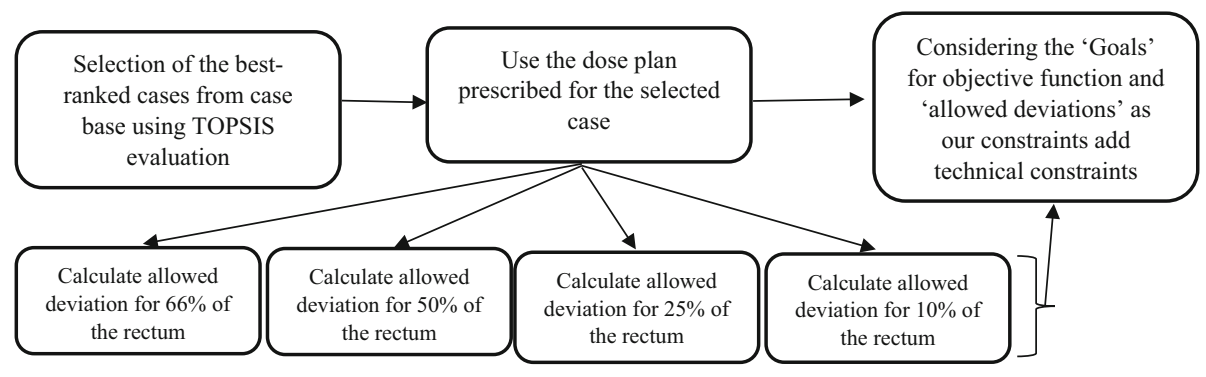

Fig. 5 The process of modeling GP problem by using CBR and TOPSIS results 
CBR-TOPSIS and DVH values related to the new case based on Eq. 12, allowed deviations from different volume percentages of the rectum $\left(S_{v}^{p}\right)$ is calculated. Through Objectives 1-3 the goals for GP are set and with the help of the calculated allowed deviations the hard constraints of the GP are defined.

The mathematical formulation for integer goal programming related to prostate cancer dose planning process is as follows:

$$
\begin{gathered}
\min Z=\sum_{j=1}^{3}\left(w_{k} d_{k}^{+}+w_{k} d_{k}^{-}\right) \\
x_{1}+x_{2}-d_{1}^{+}+d_{1}^{-}=g_{1} \\
x_{1}-d_{2}^{+}+d_{2}^{-}=g_{2} \\
x_{2}-d_{3}^{+}+d_{3}^{-}=g_{3} \\
D V H_{66 \%}^{1 p} x_{1}+D V H_{66 \%}^{2 p} x_{2}+S_{66 \%}^{p} \leq 45 ; \\
D V H_{50 \%}^{1 p} x_{1}+D V H_{50 \%}^{2 p} x_{2}+S_{50 \%}^{p} \leq 55 ; \\
D V H_{25 \%}^{1 p} x_{1}+D V H_{25 \%}^{2 p} x_{2}+S_{25 \%}^{p} \leq 65 ; \\
D V H_{10 \%}^{1 p} x_{1}+D V H_{10 \%}^{2 p} x_{2}+S_{10 \%}^{p} \leq 70 ; \\
x_{1}, x_{2} \geq 0 \text { and integer; } \\
d_{1}^{+,-}, d_{2}^{+,-}, d_{3}^{+,-} \geq 0 ;
\end{gathered}
$$

where $k=1,2,3$, the goals; $x_{1}$ and $x_{2}$, dose plan in phase I and II of the treatment; $w_{j}$ weight of $k$ th goal; $d_{k}^{+}$, positive deviation from the $k$ th goal; $d_{k}^{-}$, negative deviation from the $k$ th goal; $g_{1}, g_{2}$ and $g_{3}$, goal objectives; $D V H_{66,50,25,10 \%}^{1 p}$, DVH values of the new case $\mathrm{p}$, in the first phase of treatment corresponding to $66,50,25$ and $10 \%$ of the rectum volume; $D V H_{66,50,25,10 \%}^{2 p}$, DVH values of the new case $\mathrm{p}$, in the second phase of treatment corresponding to $66,50,25$ and $10 \%$ of the rectum volume; $S_{66,50,25,10 \%}^{p}$, the amount of deviation oncologists committed corresponding to different volume percentage of rectum for the new case p.

While $x_{1}$ and $x_{2}$ are the values of dose plan in phase I and II of the treatment respectively, $x_{1}+x_{2}$ equals to total dose plan of the treatment. There are three goals (objectives) in our problem which are explained in this section above (Sect. 3.4.1) and are $k=1,2,3$ respectively in the above model. DVH values for each phase of the treatment and each percentage of the rectum volume is available in our data set (total of 8 values for each case) and $S^{p}$ for each volume of the rectum is being calculated by expression 12 .

Equation (16) is the objective function for minimizing the deviations from our goals. Equations (20)-(25) are our goal related constraints, which determine deviations from total dose plan, dose plan in Phase I and II of the treatment respectively. Equations (17)-(19) are our systematic goals which restrict the optimization process to find solutions without violating the recommended doses based on oncologists suggestions and pre-prescribed standards. Equation (24) helps to achieve positive integer values for our dose plan.

In above GP model, we try to optimize (finding a solution as much as possible near to ideal goals) the total amount of dose plan, dose in phase I and Phase II of the treatment so that we can prescribe an optimal treatment. To achieve above objective firstly we have calculated possible deviations from recommended standards (as shown in Table 2) using CBR-TOPSIS method and consider it as constraints to our goals. Thereafter, optimal combination of total dose, dose in Phase I and II of treatment is generated while satisfy the considered constraints. 


\subsection{Maximization of dose plan within safe risk zone}

If dose received by different volume percentages of rectum is within the constraint the dose plan is acceptable. The higher the total dose, more likely the probability is to kill the cancerous cells. Hence, where there are positive $S_{v}^{p}$ it means more dose can be prescribe without deviating prescribed dose limit. Higher dose can kill the cancer cells without causing any significant damage to rectum and in exchange can increase the chance of eradicating cancerous cells. In the final step modification is performed to minimize the deviation from recommended standards as described in Eq. (26).

$$
S_{v}^{p}=\left\{\begin{array}{lll}
S_{v}^{p} & \text { if } & \geq 0 \\
0 & \text { if } & \leq 0
\end{array}\right.
$$

In real life sometimes to treat cancerous cells oncologists overlook the recommended dose limit associated with different volume percentage of rectum. Similarly, in our proposed model the system will retrieve the past similar cases and based on extracted cases it will decide the dose limit associated with different volume percentage of rectum. The proposed model will overlook the recommended dose limit if oncologist has performed similar decision in the past. Once the dose limit is set, goal programing method will search for the optimal dose plan.

\subsection{Modification rule for integer programming}

Usually, dose is delivered in 2 Gy packs. Hence, dose in phase I and II of the treatment must be an even number. In order to solve the problem of odd numbers the following conditions are incorporated in programming:

1. If calculated dose in phase I or phase II of treatment is an odd number then:

a. Increase the dose by $1 \mathrm{~Gy}$. If dose received by different volume percentages of rectum violate the constraint then decrease the dose by $1 \mathrm{~Gy}$.

2. If dose plan in both Phases of the treatment is odd number then:

a. Increase the dose plan in the both phases of the treatment by $1 \mathrm{~Gy}$ and check the limitation suggested by oncologists. If violated go to step $b$.

b. Increase the dose plan in phase I by 1 Gy and decrease dose plan in phase II by 1 Gy. Check the limitation suggested by oncologists. If violated go to step c.

c. Decrease the dose plan in phase I by 1 Gy and increase dose plan in phase II by $1 \mathrm{~Gy}$. Check the limitation suggested by oncologists. If violated go to step d.

d. Decrease the dose in phase I and II of treatment by 1 Gy

\section{Numerical example}

In this section, a numerical example is considered to illustrate the execution process of proposed method. In this example a case from our database is extracted and assumed as a new case. Firstly, cases having same clinical stage or adjacent to the new case are extracted from the database. Thereafter, from extracted cases five most similar cases are retrieved and evaluated using TOPSIS method. The features value of five selected cases are depicted in Table 4. Corresponding to each five cases the numerical value of different evaluation criteria used in TOPSIS is shown in Table 5. Subsequently, distance from PIS and NIS are calculated to find closeness coefficients as shown in Table 6 . In the given example, case 4 
Table 5 Numerical value of evaluation criteria used in TOPSIS

\begin{tabular}{llllllll}
\hline Alternatives & Criteria & \multicolumn{7}{l}{} & \\
\cline { 2 - 7 } & $\begin{array}{l}\text { Dose plan } \\
\text { in Phase I }\end{array}$ & $\begin{array}{l}\text { Dose plan } \\
\text { in Phase II }\end{array}$ & $\begin{array}{l}\text { Deviation } \\
S_{66 \%}\end{array}$ & $\begin{array}{l}\text { Deviation } \\
S_{50 \%}\end{array}$ & $\begin{array}{l}\text { Deviation } \\
S_{25 \%}\end{array}$ & $\begin{array}{l}\text { Deviation } \\
S_{10 \%}\end{array}$ & $\begin{array}{l}\text { Similarity } \\
\text { measure } \\
(\%)\end{array}$ \\
\hline Case 1 & 54 & 18 & 9.36 & 13.78 & 3.26 & 0.56 & 92.08 \\
Case 2 & 46 & 24 & 10 & 15.6 & 2.04 & 3.78 & 83.51 \\
Case 3 & 46 & 24 & 10.26 & 11.26 & 0.5 & 0.94 & 83.06 \\
Case 4 & 46 & 24 & 6.98 & 11.88 & 0.78 & 1.16 & 79.4 \\
Case 5 & 46 & 24 & 8.6 & 16.98 & 2.26 & 1.4 & 79.15 \\
\hline
\end{tabular}

Table 6 Distance from positive and negative ideal solution

\begin{tabular}{lllll}
\hline & NIS & PIS & CC & Rank \\
\hline Case 1 & 0.012004 & 0.0078994 & 0.60311 & 3 \\
Case 2 & 0.0015172 & 0.014866 & 0.092607 & 5 \\
Case 3 & 0.016934 & 0.0011271 & 0.9376 & 2 \\
Case 4 & 0.014567 & 0.0009643 & 0.93791 & 1 \\
Case 5 & 0.0072704 & 0.0051079 & 0.58735 & 4 \\
\hline
\end{tabular}

Table 7 Deviations from recommended dose limit

\begin{tabular}{lllll}
\hline Rectum volume & $66 \%$ of rectum & $50 \%$ of rectum & $25 \%$ of rectum & $10 \%$ of rectum \\
\hline Allowed deviations & -10.7200 & -15.6400 & -5.2000 & -0.9400 \\
\hline
\end{tabular}

Table 8 Average similarity measure between first $t$ similar case and a new case

\begin{tabular}{llllll}
\hline $\begin{array}{l}\text { Number of similar } \\
\text { cases }\end{array}$ & $\mathrm{t}=3$ & $\mathrm{t}=4$ & $\mathrm{t}=5$ & $\mathrm{t}=6$ & $\mathrm{t}=7$ \\
\hline $\begin{array}{l}\text { Average similarity } \\
\text { measures }\end{array}$ & $85.2 \%$ & $83.6 \%$ & $81.1 \%$ & $70.5 \%$ & $63.2 \%$ \\
\hline
\end{tabular}

has higher closeness coefficient compared to other cases and thus is selected as our guide (as an oncologist opinion) to calculate deviations from recommended standard. Thereafter, with the help of Eq. (12) the deviations from recommended dose limit is calculated as illustrated in Table 7.

We have selected initial number of similar cases (i.e. five in this study) based on average similarity measure between a new case and cases in the case base. One-by-one all the cases from the data base have been retrieved and treated as a new case and average similarity measure between $t=3,4,5,6$ and 7 most similar cases to them was calculated and results are shown in Table 8. During experiments it was found that as we move forward from 5 to 6 similar cases the average similarity measure of $t$ cases with the new case significantly reduces from 81.1 to $70.5 \%$ and moreover some outliers with less than $50 \%$ similarity to a new case were found. Based on above fact in this article we have retrieved 5 most similar cases as our initial number for the dose planning process. 
To optimize the dose plan goal programming is formulated. Based on the expert opinion of oncologists the weight associated with total dose, dose in phase I and II of treatment are set as $0.70,0.25$ and 0.05 respectively. Here, higher weight is assigned to the total dose of treatment to maximize the overall recommended dose. When the maximum total dose is achieved the next goal is to maximize the dose in phase I of the treatment. In Nottingham City Hospital maximum total dose, highest dose in phase I and II of treatment are prescribed as 74, 64 and 14 Gy respectively. Hence, in our model constraint related to maximum total dose, dose in phase I and II of treatment is set as 74, 64 and 14 Gy respectively.

The overall goal programming for the selected case is as follows:

$$
\begin{aligned}
& \min Z=0.7 d_{1}^{+}+0.7 d_{1}^{-}+0.25 d_{2}^{-}+0.05 d_{3}^{-} \\
& x_{1}+x_{2}-d_{1}^{+}+d_{1}^{-}=74 \\
& x_{1}-d_{2}^{+}+d_{2}^{-}=64 \\
& x_{2}-d_{3}^{+}+d_{3}^{-}=14 \\
& D V H_{66 \%}^{1} x_{1}+D V H_{66 \%}^{2} x_{2}+10.72 \leq 45 \\
& D V H_{50 \%}^{1} x_{1}+D V H_{50 \%}^{2} x_{2}+15.64 \leq 55 \\
& D V H_{25 \%}^{1} x_{1}+D V H_{25 \%}^{2} x_{2}+5.2 \leq 65 \\
& D V H_{10 \%}^{1} x_{1}+D V H_{10 \%}^{2} x_{2}+0.94 \leq 70 \\
& x_{1}, x_{2} \geq 0 \text { and integer; } \\
& d_{1}^{+,-}, d_{2}^{+,-}, d_{3}^{+,-} \geq 0 ;
\end{aligned}
$$

Based on three objectives considered for the problem (Sect. 3.4.1) and explanation in Sect. 3.4.1 on positive and negative goal deviations, here in this problem we try to minimize both $d_{1}^{+}$and $d_{1}^{-}$to direct the final results as much as possible towards the maximum amount of total dose plan available. Also, in order to achieve the equal or higher amount of available dose plans in phase I and II of the treatment we only try to minimize the undesirable negative deviations of $d_{2}^{-}$and $d_{3}^{-}$.

Due to positive values of DVH violations $\left(S^{p} \geq 0\right)$, there is a scope for improvement. To determine the dose limit of different volume percentage of rectum we eliminate all the $S^{k}$ based on what we described in Sect. 3.5. After solving the linear integer goal programming the value of dose in Phase I and II of treatment is 56 and 14 GY respectively, which is within the safe recommended limit without exceeding recommended standards.

\section{Experimental results}

In order to examine effectiveness of the proposed methodology we applied an approach called leave one out strategy. Anonymous patient records of past treated patients are collected from Nottingham City Hospital and stored in the database. In our database we have total 69 cases. In leave-one-out approach, cases stored in our case base are extracted one-by-one and considered as a new case. The dose plan related to each of the taken out cases is calculated through the proposed methodology and the result is compared with the dose plan prescribed by oncologist. If there is any discrepancy among the dose plan computed by our methodology and the prescribed by the oncologists' then firstly dose received by different volume percentage 
of rectum is calculated. If dose received by the different volume percentages of rectum are less than or equal to the recommended limit then the quality of dose plan is judged based on following conditions. The dose plan having higher amount of total dose is considered as a better dose plan compared to other because while radiation received by rectum is in safe zone (lower than recommended standards) the probability of killing cancerous cells without damaging surrounding organs, specially rectum, is higher and chances for patient to live cancer free will be higher thus a dose plan having maximum amount of total dose will help to kill cancerous cells more efficiently and simultaneously oncologists can be confident about side effects of the treatment (Mishra et al. 2011). However, if two plans have same amount of total dose then the quality of the plan is judged based on amount of dose prescribed in Phase I of treatment. In Phase I of the treatment both cancer and its surrounding organs where cancer has spread is treated. The dose plan having higher amount of dose in phase I of treatment is considered as better dose plan compared to other dose plans which have less amount of dose in phase I of treatment. If the dose plan generated by the proposed system is equal or better (based on abovementioned criteria) compared with oncologist prescription then it is considered as a successful case.

The success rate of proposed method is $87.6 \%$. In 57 cases (out of 65 cases) dose plan suggested by proposed method is same as prescribed by oncologist or even better. More precisely, in 29 cases it generates a better dose plan. Further in order to demonstrate the suitability of TOPSIS and goal programing method it is compared with CBR and CBR-TOPSIS as shown in Table 9 and Fig. 6. It can be noticed that the performance of CBR-TOPSIS Goal programing is better than other approaches.

Table 9 Comparison of the proposed methodology with approaches

\begin{tabular}{lllll}
\hline Different approaches & Simple CBR & CBR+TOPSIS & $\begin{array}{l}\text { CBR+TOPSIS + } \\
\text { Modification rule }\end{array}$ & $\begin{array}{l}\text { CBR+TOPSIS + } \\
\text { GP }\end{array}$ \\
\hline $\begin{array}{l}\text { Success rate }(\%) \\
\begin{array}{c}\text { Number of cases with } \\
\text { better dose plan }\end{array}\end{array}$ & 73.43 & 83.6 & 86.88 & 87.6 \\
\hline
\end{tabular}

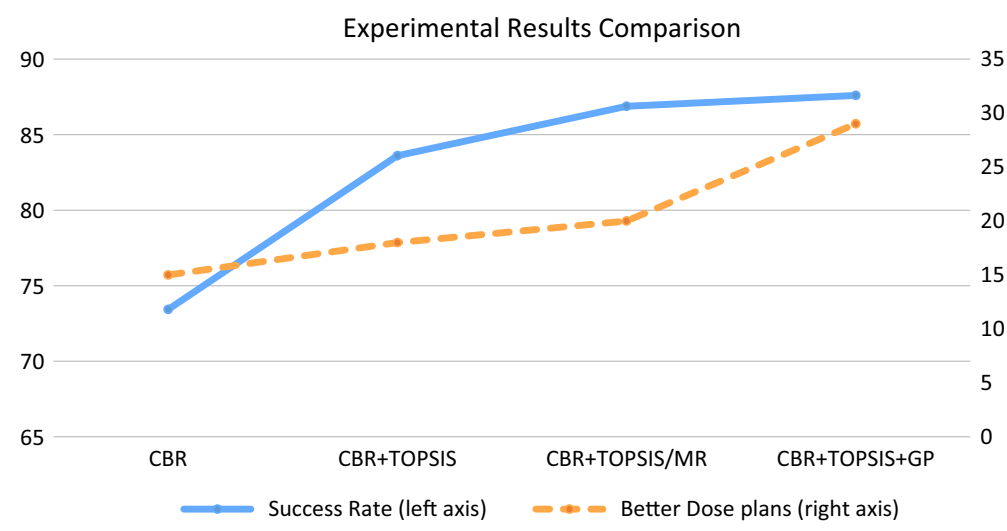

Fig. 6 Graphical representation of success rate 
Table 10 success rate of the approach by considering different number of similar cases

\begin{tabular}{llllll}
\hline Success rate & \multicolumn{4}{l}{ Number of cases } & \\
\cline { 2 - 6 } & $\mathrm{t}=3$ & $\mathrm{t}=4$ & $\mathrm{t}=5$ & $\mathrm{t}=6$ & $\mathrm{t}=7$ \\
\hline $\begin{array}{l}\text { Success rate (\%) with CBR+ } \\
\quad \text { TOPSIS + GP approach }\end{array}$ & 75.3 & 80 & 87.6 & 87.6 & 87.6 \\
$\begin{array}{l}\text { Number of cases with better dose } \\
\text { plan }\end{array}$ & 17 & 21 & 29 & 29 & 29 \\
\hline
\end{tabular}

Also in order to further consider the number of retrieved most similar cases to be considered in TOPSIS evaluation, the whole experiment has been done for $t=3,4,5,6$, and 7 most similar case to a new case and results are shown in Table 10. Increasing the number of most similar cases from 4 to 5 , success rate of the process increased by $7.6 \%$. Increasing the number of cases from 5 to 6 to 7 cases did not have any effect on the outcome of the process simply because the extra similar cases due to their low similarity to the new case, were not evaluated effective by TOPSIS to be considered as the reference case for GP optimization.

\section{Conclusion}

Health is an essential component of sustainable human development. Better treatment in minimum cost by adopting new technology will empower sustainable development of society. Cancer is one of the most common diseases worldwide. In this paper a novel approach to radiotherapy dose planning is proposed and results have been precisely investigated. A three stages approach is recommended. In the first step cases similar to the new case are extracted from the database using case based reasoning approach. In experiment it was found that sometimes a case is similar to the new case but has low success rate compared to other non-similar cases. In real life similarity measure is not only a decisionmaking parameters. In decision-making process oncologist make a trade-off between various parameters. Also, to treat cancerous cells sometime oncologist overlooks recommended dose limit. The amount of deviation from recommended limit is usually based on oncologists' past experience'. To accomplish the same, extracted five most similar cases are evaluated using TOPSIS, a multi criteria decision-making technique and dose limit of different volume percentage of rectum is calculated. Finally, goal programming is used to decide optimal dose in phase I and II of treatment. The robustness of proposed method is tested on real data sets collected from Nottingham City Hospital using leave-one-out strategy. In experiments it was found that proposed system not only help oncologists to make a trade-off between different decision-making criteria, but also help to decide optimal dose plan for the treatment. In future, some extra parameters such as fitness of patients, side effects during and after the treatment can be taken into account in CBR system.

Open Access This article is distributed under the terms of the Creative Commons Attribution 4.0 International License (http://creativecommons.org/licenses/by/4.0/), which permits unrestricted use, distribution, and reproduction in any medium, provided you give appropriate credit to the original author(s) and the source, provide a link to the Creative Commons license, and indicate if changes were made. 


\section{Appendix: Medical features used in Table 2}

\begin{tabular}{|c|c|}
\hline Clinical stage & $\begin{array}{l}\text { A labelling system indicating the local extent of a prostate tumor and its spread to } \\
\text { surrounding organs. It includes } \mathrm{T} 1 \mathrm{a}, \mathrm{T} 1 \mathrm{~b}, \mathrm{~T} 1 \mathrm{c}, \mathrm{T} 2 \mathrm{a}, \mathrm{T} 2 \mathrm{~b}, \mathrm{~T} 3 \mathrm{a}, \mathrm{T} 3 \mathrm{~b} \text { categories }\end{array}$ \\
\hline DVH & $\begin{array}{l}\text { A graphical representation of the dose that is received by normal tissues and target } \\
\text { volumes within a 3-D radiation therapy plan. They provide information on the volume } \\
\text { of a structure receiving a given dose over a range of doses. In Prostate cancer } \\
\text { radiotherapy, rectum's volumes of interest are } 66,50,25 \text { and } 10 \%\end{array}$ \\
\hline Gleason Score & $\begin{array}{l}\text { A classification of prostate cancer grade on the basis of histology with predictive value for } \\
\text { progression. The values are in range of } 1-10 \text {. Cancers with a higher Gleason score are } \\
\text { more aggressive and have a worse prognosis }\end{array}$ \\
\hline PSA & $\begin{array}{l}\text { Prostate Specific Antigen, The PSA test measures the level of PSA in a man's blood. } \\
\text { Elevated amounts of PSA could be result of inflammation of the prostate, infection or } \\
\text { prostate cancer. The values are within the range of } 1-40\end{array}$ \\
\hline
\end{tabular}

\section{References}

Alptekin, G. I., \& Büyüközkan, G. (2011). An integrated case-based reasoning and MCDM system for Web based tourism destination planning. Expert Systems with Applications, 38(3), 2125-2132.

Armaghan, N., \& Renaud, J. (2012). An application of multi-criteria decision aids models for case-based reasoning. Information Sciences, 210, 55-66.

Ayeldeen, H., Shaker, O., Hegazy, O., \& Hassanien, A. E. (2015). Case-based reasoning: A knowledge extraction tool to use. In Information systems design and intelligent applications (pp. 369-378).

Balubaid, M. A., \& Basheikh, M. A. (2016). Using the analytic hierarchy process to prioritize alternative medicine: Selecting the most suitable medicine for patients with diabetes. International Journal of Basic and Applied Sciences, 5(1), 67.

Banihabib, M.E., Hashemi, F., \& Shabestari, M. H. (2016). A Framework for sustainable strategic planning of water demand and supply in arid regions. Sustainable Development.

Begum, S., Ahmed, M. U., Funk, P., Xiong, N., \& Folke, M. (2011). Case-based reasoning systems in the health sciences: a survey of recent trends and developments. IEEE Transactions on Systems, Man, and Cybernetics, Part C: Applications and Reviews, 41(4), 421-434.

Bertsimas, D., Cacchiani, V., Craft, D., \& Nohadani, O. (2013). A hybrid approach to beam angle optimization in intensity-modulated radiation therapy. Computers \& Operations Research, 40(9), 2187-2197.

Bichindaritz, I., \& Marling, C. (2006). Introduction to the special issue on cased-based reasoning in the health science. Computational Intelligence, 22(3-4), 143-147.

Bondor, C. I., Kacso, I. M., Lenghel, A., Istrate, D., \& Muresan, A. (2013). VIKOR method for diabetic nephropathy risk factors analysis. Applied Medical Informatics, 32(1), 43-52.

Büyüközkan, G., Çifçi, G., \& Güleryüz, S. (2011). Strategic analysis of healthcare service quality using fuzzy AHP methodology. Expert systems with applications, 38(8), 9407-9424.

Brasil Filho, A. T., Pinheiro, P. R., \& Coelho, A. L. (2009). Towards the early diagnosis of Alzheimer's disease via a multicriteria classification model. In International conference on evolutionary multi-criterion optimization (pp. 393-406). Heidelberg: Springer.

Chai, J., Liu, J. N. K., \& Ngai, E. W. T. (2013). Application of decision-making techniques in supplier selection: A systematic review of literature. Expert Systems with Applications, 40(10), 3872-3885.

Chan, T. C., Craig, T., Lee, T., \& Sharpe, M. B. (2014). Generalized inverse multiobjective optimization with application to cancer therapy. Operations Research, 62(3), 680-695.

Chang, T. H. (2014). Fuzzy VIKOR method: a case study of the hospital service evaluation in Taiwan. Information Sciences, 271, 196-212.

Chung, K. P., Chen, L. J., Chang, Y. J., Chang, Y. J., \& Lai, M. S. (2012). Application of the analytic hierarchy process in the performance measurement of colorectal cancer care for the design of a pay-for-performance program in Taiwan. International journal for quality in health care, 25(1), 81-91.

Chuang, C. L. (2013). Application of hybrid case-based reasoning for enhanced performance in bankruptcy prediction. Information Sciences, 236, 174-185. 
Clark, V. H., Chen, Y., Wilkens, J., Alaly, J. R., Zakaryan, K., \& Deasy, J. O. (2008). IMRT treatment planning for prostate cancer using prioritized prescription optimization and mean-tail-dose functions. Linear Algebra and its Applications, 428(5), 1345-1364.

Diaz-Ledezma, C., \& Parvizi, J. (2013). Surgical approaches for cam femoroacetabular impingement: the use of multicriteria decision analysis. Clinical Orthopaedics and Related Research $囚, 471(8), 2509-2516$.

Ferrari, M. D., Goadsby, P. J., Lipton, R. B., Dodick, D. W., Cutrer, F. M., McCrory, D., et al. (2005). The use of multi-attribute decision models in evaluating triptan treatment options in migraine. Journal of Neurology, 252(9), 1026-1032.

Fiege, J., McCurdy, B., Potrbko, P. S., Champion, H., \& Cull, A. (2011). PARETO: A novel evolutionary optimization approach to multiobjective IMRT planning. Medical Physics, 38(9), 5217-5229.

Garcia-Bernabeu, A., Benito, A., Bravo, M., \& Pla-Santamaria, D. (2016). Photovoltaic power plants: A multi-criteria approach to investment decisions and a case study in western Spain. Annals of Operations Research, 245(1-2), 163-175.

Govindan, K., \& Sivakumar, R. (2016). Green supplier selection and order allocation in a low-carbon paper industry: Integrated multi-criteria heterogeneous decision-making and multi-objective linear programming approaches. Annals of Operations Research, 238(1-2), 243-276.

Hartati, S., Ermatita, Harjoko, A., \& Wardoyo, R. (2012). ELECTRE-entropy method in group decision support system model to gene mutation detection. International Journal of Advanced Research in Artificial Intelligence, $1(1), 58-63$.

Holder, A., \& Salter, B. (2005). A tutorial on radiation oncology and optimization. In Tutorials on emerging methodologies and applications in operations research (pp. 4-1-4-45). New York: Springer.

Hu, J., \& Sun, J. (2016). A case-based reasoning method with relative entropy and TOPSIS integration. In F. Xhafa, S. Patnaik, \& Z. Yu (Eds.), Recent developments in intelligent systems and interactive applications. IISA 2016. Advances in intelligent systems and computing (Vol. 541, pp. 102-109). Berlin: Springer.

Hummel, M. J., Volz, F., Van Manen, J. G., Danner, M., Dintsios, C. M., Ijzerman, M. J., et al. (2012). Using the analytic hierarchy process to elicit patient preferences: prioritizing multiple outcome measures of antidepressant drug treatment. Patient, 5(4), 225-237.

Hwang, C. L., \& Yoon, K. (1981). Multiple attribute decision making. In Lecture notes in economics and mathematical systems (Vol. 186). Springer.

Kahraman, C., Süder, A., \& Kaya, I. (2014). Fuzzy multicriteria evaluation of health research investments. Technological and Economic Development of Economy, 20(2), 210-226.

Kolodner, J. L. (1993). Case-based reasoning. Burlington: Morgan Kaufmann.

La Scalia, G., Aiello, G., Rastellini, C., Micale, R., \& Cicalese, L. (2011). Multi-Criteria decision making support system for pancreatic islet transplantation. Expert Systems with Applications, 38(4), 3091-3097.

Li, H., Adeli, H., Sun, J., \& Han, J. G. (2011). Hybridizing principles of TOPSIS with case-based reasoning for business failure prediction. Computers \& Operations Research, 38(2), 409-419.

Liu, H. C., You, J. X., Lu, C., \& Shan, M. M. (2014). Application of interval 2-tuple linguistic MULTIMOORA method for health-care waste treatment technology evaluation and selection. Waste Management, 34(11), 2355-2364.

Lopez, D., \& Gunasekaran, M. (2015). Assessment of vaccination strategies using fuzzy multi-criteria decision making. In Proceedings of the fifth international conference on fuzzy and neuro computing (FANCCO2015) (pp. 195-208). Springer.

Malekpoor, H., Mishra, N., Sumalya, S., \& Kumari, S. (2017). An efficient approach to radiotherapy dose planning problem: A TOPSIS case-based reasoning approach. International Journal of Systems Science: Operations \& Logistics, 4(1), 4-12.

Malviya, R. K., \& Kant, R. (2016). Hybrid decision making approach to predict and measure the success possibility of green supply chain management implementation. Journal of Cleaner Production, 135, 387-409.

Marques, I., Captivo, M. E., \& Pato, M. V. (2012). An integer programming approach to elective surgery scheduling. OR spectrum, 34(2), 407-427.

Mishra, N., Petrovic, S., \& Sundar, S. (2011). A self-adaptive case-based reasoning system for dose planning in prostate cancer radiotherapy. Medical Physics, 38(12), 6528-6538.

National Cancer Institue. Prostate cancer. Online available at: http://www.cancer.gov/cancertopics/types/pro state. Accessed 1 Aug 2016.

Oliveira, M., Fontes, D. B., \& Pereira, T. (2013). Multi-criteria decision making: A case study in the automobile industry. Porto: Portugal, School of Economics and Management, University of Porto.

Othman, M. K., Fadzil, M. N., \& Rahman, N. S. F. A. (2015). The Malaysian Seafarers psychological distraction assessment using a TOPSIS method. International Journal of e-Navigation and Maritime Economy, 3, 40-50. 
Petrovic, S., Mishra, N., \& Sundar, S. (2011). A novel case based reasoning approach to radiotherapy planning. Expert Systems with Applications, 38(9), 10759-10769.

Piegat, A., \& Sałabun, W. (2015). Comparative analysis of MCDM methods for assessing the severity of chronic liver disease. In International conference on artificial intelligence and soft computing (pp. 228-238). Springer.

Ping, X. O., Tseng, Y. J., Lin, Y. P., Chiu, H. J., Lai, F., Liang, J. D., et al. (2015). A multiple measurements casebased reasoning method for predicting recurrent status of liver cancer patients. Computers in Industry, 69, 12-21.

Pugachev, A., \& Xing, L. (2002). Incorporating prior knowledge into beam orientation optimization in IMRT. International Journal of Radiation Oncology Biology Physics, 54(5), 1565-1574.

Rahimi, S. A., Jamshidi, A., Ait-Kadi, D., \& Bartolome, A. R. (2015). Risk-based decision making framework for prioritizing patients' access to healthcare services by considering uncertainties. In 2015 international conference on industrial engineering and systems management (IESM) (pp. 291-297). IEEE.

Romeijn, H. E., Ahuja, R. K., Dempsey, J. F., \& Kumar, A. (2006). A new linear programming approach to radiation therapy treatment planning problems. Operations Research, 54(2), 201-216.

Santos, F. A. \& Garcia, R. (2010). Decision process model to the health technology incorporation. In Engineering in Medicine and Biology Society (EMBC) 2010 annual international conference of the IEEE (pp. 414-417). IEEE.

Sharaf-El-Deen, D. A., Moawad, I. F., \& Khalifa, M. E. (2014). A new hybrid case-based reasoning approach for medical diagnosis systems. Journal of Medical Systems, 38(2), 1-11.

Slade, S. (1991). Case-based reasoning: A research paradigm. AI magazine, 12(1), 42.

Streimikiene, D., Balezentis, T., Krisciukaitienè, I., \& Balezentis, A. (2012). Prioritizing sustainable electricity production technologies: MCDM approach. Renewable and Sustainable Energy Reviews, 16(5), 3302-3311.

Tadić, S., Zečević, S., \& Krstić, M. (2014). A novel hybrid MCDM model based on fuzzy DEMATEL, fuzzy ANP and fuzzy VIKOR for city logistics concept selection. Expert Systems with Applications, 41(18), 8112-8128.

Taghipour, S., Banjevic, D., \& Jardine, A. K. (2011). Prioritization of medical equipment for maintenance decisions. Journal of the Operational Research Society, 62(9), 1666-1687.

Tang, Y. C., \& Chang, C. T. (2012). Multicriteria decision-making based on goal programming and fuzzy analytic hierarchy process: An application to capital budgeting problem. Knowledge-Based Systems, 26, 288-293.

Teodorovic, D., Selmic, M., \& Miatovic, L. (2013). Combining case base reasoning with bee colony optimization for dose planning in well differentiated thyroid cancer treatment. Expert Systems with Applications, 40(6), 2147-2155.

Tsai, W. H., Hsu, J. L., Chen, C. H., Lin, W. R., \& Chen, S. P. (2010). An integrated approach for selecting corporate social responsibility programs and costs evaluation in the international tourist hotel. International Journal of Hospitality Management, 29(3), 385-396.

Tzeng, G. H., \& Huang, C. Y. (2012). Combined DEMATEL technique with hybrid MCDM methods for creating the aspired intelligent global manufacturing \& logistic ssystems. Annals of Operations Research, 197(1), 159-190.

Uzoka, F. M. E., Osuji, J., \& Obot, O. (2011). Clinical decision support system (DSS) in the diagnosis of malaria: A case comparison of two soft computing methodologies. Expert Systems with Applications, 38(3), 1537-1553.

Vidal, L. A., Sahin, E., Martelli, N., Berhoune, M., \& Bonan, B. (2010). Applying AHP to select drugs to be produced by anticipation in a chemotherapy compounding unit. Expert Systems with Applications, 37(2), 1528-1534.

Yin, Z., Dong, Z., Lu, X., Yu, S., Chen, X., \& Duan, H. (2015). A clinical decision support system for the diagnosis of probable migraine and probable tension-type headache based on case-based reasoning. The journal of headache and pain, 16(1), 29. 